\title{
nature
}

\section{Whither high-energy physics?}

Last week's meeting of the CERN council has sharpened the dilemma of those who suck their teeth about the cost of high-energy physics. The time has come to plan for wider collaboration.

IT is a great relief that the British government told the CERN council at Geneva last week (see p. 681) that it intends to stay a member of the organization, but that CERN (the European Organisation for Nuclear Research) must find ways of cheapening both its total cost and the cost of membership. It would have been a great misfortune for Britain and, to a lesser extent, for CERN if Britain had withdrawn. The hope now must be that the legitimate pursuit of economies stops short of damaging CERN's scientific programme. The ideal should be that the whole contentious episode should be concluded at the special meeting of the council that is due to take place in two months' time.

Meanwhile, in the administration of British civil science, the need is now more urgent than ever that the budget of the Science and Engineering Research Council should in future be insulated from the fluctuations of the cost of membership arising from fluctuations of the relative cost of sterling and Swiss francs. If, on the grounds of general financial policy, the British government manipulates the value of sterling so as to retain some relationship with the US dollar, but the Swiss government does not, can it be said to be equitable that there should then be less money to spend on the general support of academic research in Britain?

That is a domestic issue for the British, but the report of the committee under Professor Anatole Abragam, set up to identify potential economies in CERN's high-energy physics, provides other members of CERN with an interesting opportunity. The report is both supportive and critical of CERN. Abragam and his colleagues are full-throated in their applause for CERN's achievement as a high-energy physics laboratory, and for its plans for the years ahead, which is only right and proper. Their criticisms are of a managerial character: the working committee responsible for CERN's policy between council meetings has grown too big; liaison with industry and even scientific users should be improved; the costs of informal arrangements with high-energy physicists outside the CERN membership are often unrequited; the permanent staff includes 300 people who will not be needed in the $1990 \mathrm{~s}$; and too great a proportion ( 86 per cent) of the full-time staff at Geneva (3,500 in total) enjoy indefinite employment contracts.

\section{Wider interests}

To be fair to CERN's present generation of managers, most of Abragam's complaints are implicitly levelled at previous decisions (sometimes taken by default) of the governing council, which is also responsible for the prevalence of the salary supplements enjoyed by those who work at CERN (who are also exempt from income taxes). But it is in the wider interest, not just that of keeping the British government quiet, that Abragam's recommendations should be followed energetically. As the committee report puts it, CERN exists to serve the European high-energy physics community, without which it would have no independent existence, and must therefore be an integral part of it. This is the spirit in which the committee would have CERN shed 300 people sooner rather than later, and would reduce the proportion of people on indefinite contracts to below a half. The report also has sensible things to say about the relationship between the laboratory and its social environment, that of Switzerland and France, which could lead to further reductions of employment costs. But with the best will in the world, the savings in the annual budget will amount to only 10 per cent or so, less than the British government had been hoping for

Meanwhile, plans are being drawn for the further development of CERN. Last week's council meeting was presented not merely with the Abragam report but with a document from CERN's own committee under Carlo Rubbia set up to work out plans for the distant future. Like much else of what CERN does, the forward plan is at once imaginative and convincing.

\section{Proposals}

The version of LEP (for Large Electron-Positron collider) now being built will arrange for the collision of $50-\mathrm{GeV}$ electrons and positrons, but it is intended that the energy of each beam should be increased to $100 \mathrm{GeV}$ by the use of more powerful magnetic fields. What the Rubbia committee argues is that, even then, much interesting physics will be out of range, and that crucial tests of current theories of particle physics will come only at a collision energy two orders of magnitude greater, at $10 \mathrm{TeV}$ or thereabouts. So the committee advocates two developments the use of the LEP tunnel ( $27 \mathrm{~km}$ in circumference) to arrange for the collision of protons and electrons and the construction of a novel electron-collider based on two linear accelerators accelerating particles to more than $1 \mathrm{TeV}$. (Such a scheme has also been proposed by the Nuclear Physics Institute at Novosibirsk, and may yet be built at Serpukhov.)

All this is fine and dandy. Implemented, one or other of these plans would help to keep European high-energy physics on a par with that in the United States and the Soviet Union (not to mention whatever may be happening in Japan in the year 2000). The obvious difficulty is that the costs, estimated only roughly for last week's meeting, are bound to be very great, while full utilization of the new machines (if built) would require the maintenance of the European high-energy physics community at roughly its present size. Is that not a recipe for future trouble, not necessarily with the British then but with some other member state? That is why it would make sense if, in the wake of the Abragam report, CERN were to take the initiative with proposals for fuller (and no doubt more effective) collaboration on the construction of the next generation of accelerators. Everybody in the field acknowledges that the time must come when particle accelerators are built on a thoroughly international basis - then, however, follows latter-day Saint Augustine with the predictable reservation ". . . but not yet". As it happens, CERN has unique experience of international collaboration at work, and is best placed to propose to a wider range of partners means by which fuller collaboration might be organized. Nobody would blame it if others' chauvinism caused it to fail, but CERN will have only itself to blame for the consequences of not trying. 